\title{
Characterization of Tin Pest Phenomenon in a Low Ag Content SAC Solder Alloy
}

\author{
Balázs Illés ${ }^{1)}$, Agata Skwarek ${ }^{2)}$, Tamás Hurtony ${ }^{1)}$, Olivér Krammer ${ }^{1)}$, Gábor Harsányi ${ }^{1)}$, \\ and Krzysztof Witek ${ }^{2)}$ \\ ${ }^{1)}$ Budapest University of Technology and Economics, Department of Electronics \\ Technology, \\ Budapest, Egry József u. 18, 1111 Hungary \\ 2) Łukasiewicz Research Network - Institute of Electron Technology, Kraków Division, \\ Kraków, ul. Zabłocie 39, 30-701 Poland \\ +36-1-4632755, billes@ett.bme.hu
}

\begin{abstract}
In the electronics technology, the metallic $\beta$-Sn (white tin) is the basic material of solder alloys and surface finishes. The "tin pest" phenomenon is the spontaneous allotropic transition of $\beta-S n$ to the semiconductor $\alpha$-Sn (gray tin) under the temperature of $13.2^{\circ} \mathrm{C}$. In this work, the tin pest susceptibility of the widely used Sn99Ag0.3Cu0.7 solder alloy was investigated and compared to Sn99Cu1 alloy (as a well know reference). Bulk solder bars were prepared by metal casting and the samples were inoculated by $\mathrm{InSb}, \mathrm{CdTe}$ and $\alpha$-Sn powders to enhance the allotropic transition process. The inoculator materials were pressed onto the surfaces of the samples by a mechanic lamination. The samples were stored at $-10{ }^{\circ} \mathrm{C}$ temperature for 8 weeks. The allotropic transition was monitored by optical inspection and by electrical resistance measurements. The microstructural changes of the samples - caused by the transition of crystal structure of $\mathrm{Sn}$ - were investigated by metallurgical cross-sections. The results showed, that in all cases the $\mathrm{Sn} 99 \mathrm{Ag} 0.3 \mathrm{Cu} 0.7$ solder alloy is much less susceptible to tin pest development than the $\mathrm{Sn} 991 \mathrm{Cu}$, which might be explained by the suppression effect of the Ag alloying. Furthermore, it was found that the process of transition highly depends on the applied inoculator material.
\end{abstract}

Key words: soldering; tin pest; SAC alloy; inoculator; allotrope transition;

\section{Introduction}

In the electronics technology, the metallic $\beta$-Sn (white tin) is the basic material of solder alloys and surface finishes [1]. $\beta$-Sn has BCT crystal structure, and it is stable temperature 
above $13.2^{\circ} \mathrm{C}$ (with the melting point at $231.9^{\circ} \mathrm{C}$ ). Sn has further three more allotropes the $\alpha-$, $\gamma$ - and $\sigma-S n$. From the aspect of microelectronics applications, the $\gamma$ - and $\sigma$-Sn are less known, since they can from only at harsh conditions, temperature above $161^{\circ} \mathrm{C}$ and pressures above several GPa in high pressure [2]. $\alpha$-Sn (gray Sn) has diamond cubic crystal structure and it is stable temperature below $13.2^{\circ} \mathrm{C} . \alpha-\mathrm{Sn}$ is a nonmetallic material, since its atoms are in covalent structure, in which electrons are not freely movable. It is a semiconductor and powdery material.

So called "tin pest" phenomenon marks the allotropic transition of $\beta$ to $\alpha$-Sn below $13.2^{\circ} \mathrm{C}$ [3]. The first sign of the transition is the appearance of discolored spots / warts on the surface of the objects, (Fig. 1). Further result of the transition is the decomposition of the objects into powder, since the transition causes $\sim 27 \%$ volume increase [4]. The allotropic transition can have three main phases: "the nucleation", when new phases starts to develop via self-organization or new thermodynamic phases form; "the growth", when the transition proceeds and "the saturation", when the transition stops, and some $\alpha$-Sn remains in metastable state [5]. The speed of the transition highly depends on the temperature and the presence of materials with the same crystal structure with similar lattice parameters to the $\alpha$-Sn, like CdTe or InSb [6].

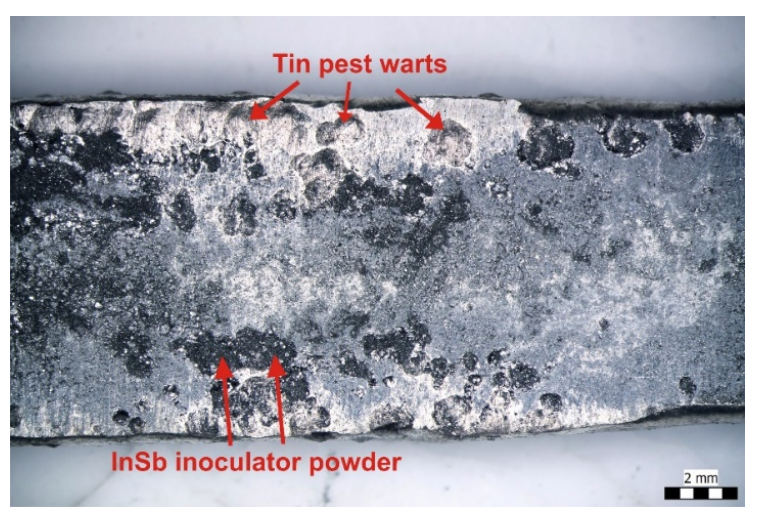

Figure 1: Tin pest warts on the surface of Sn99Ag0.3Cu0.7 alloy inoculated with InSb after 10 weeks of storage at $-10^{\circ} \mathrm{C}$.

Tin pest can occur not only in pure Sn objects, but in high Sn content alloys as well [3, 6]. However, alloying of electropositive metals (like $\mathrm{Pb}, \mathrm{Bi}, \mathrm{Sb}$ ), which are soluble in the solid Sn, usually suppress the transition [7]. After the application of RoHS directives since 2006, mostly the lead-free $\mathrm{SnAgCu}$ (SAC) solder alloys are applied in microelectronics [8]. In 
these alloys, the Sn content is over than $95 \mathrm{wt} \%$, so the risk of the tin pest phenomenon might be increased considerably in microelectronic appliances $[3,6]$.

In addition, a further trend in the soldering technology is to reduce more and more expensive Ag from SAC solder alloys [9]. Among the so called "low Ag content SAC alloys", the Sn99Ag0.3Cu0.7 (SAC0307) alloy is the most widespread in the electronics industry. The solder joints made from SAC0307 have the similar quality and reliability properties (electrical conductivity, mechanical stability, long-term durability, corrosion susceptibility, etc.) as the solder joints made from the widely applied SAC305 or SAC405 alloys [10]. The price of SAC0307 is 20-30\% lower than the prices of SAC305, however, the even 99 wt\% Sn content could increase further the possibility of the allotropic transition of tin.

Consequently, the study of tin pest susceptibility of low Ag content SAC solder alloys is important for electronic devices working in sub-zero temperature in aerospace, automobile and aeronautical applications.

\section{Materials and Methods}

In this work, the tin pest susceptibility of the SAC0307 solder alloy was investigated and compared to Sn99Cu1 alloy. The tin pest susceptibility of the Sn99Cu1 alloy is well researched [5, 6]. Bulk solder bars were casted with the size of $45 \times 6 \times 3 \mathrm{~mm}$ (Fig. 2). For shortening the nucleation phase different inoculator powders: InSb, CdTe and $\alpha$-Sn itself were used.

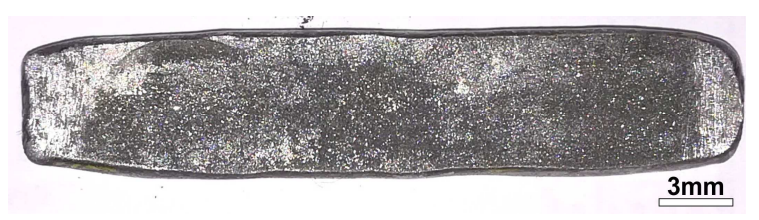

Figure 2: The inoculated sample.

Inoculating powders were pressed onto the surfaces of the samples by a mechanic laminator, applied $30 \mathrm{kN}$ force. Fifteen - fifteen samples were prepared from the six different sample types. The samples were stored at $-10{ }^{\circ} \mathrm{C}$ temperature for 8 weeks.

Basically, the tin pest development was monitored by optical inspections. After the first tin pest sign appeared, the progress of the transition was characterized by electrical resistance measurements as well, since the transition (from metal to semiconductor) increases the electrical resistance of the samples. The measurements were carried out by 4-wire method with an AGILENT 4338B $\mathrm{m} \Omega$ meter. At $\mathrm{m} \Omega$ range the measurement accuracy of the 
instrument is under $3 \%$ and the repeatability error was under $2 \%$. The initial average resistance value of the samples was between $0.23-0.25 \mathrm{~m} \Omega$.

Metallurgical cross-sections were also prepared and analyzed by an Olympus BX51 metal microscope in order study the microstructural changes of the samples caused by the changing of the crystal structure of $\mathrm{Sn}$.

\section{Results and Discussion}

Fig. 3 shows the average electrical resistance changes of Sn99Cu1 samples inoculated with InSb, CdTe and $\alpha-S n$ in logarithmic scale. During the first 3 weeks of the study, no detectable resistance change was observed. However, minor tin pest warts (see Fig. 1) already appeared on the surface of the samples after 2-3 weeks storage at $-10{ }^{\circ} \mathrm{C}$. At 4 weeks, the samples inoculated with InSb and $\alpha$-Sn showed resistance increases, between $30-150 \%$ for InSb and 5-20\% for $\alpha$-Sn inoculation. In the case of CdTe inoculation, 5-20\% resistance increase was detected only after 4 weeks of storage. Hence, the nucleation phase of the transition has been found to be 3 and 5 weeks, at InSb, $\alpha$-Sn and CdTe inoculation, respectively.

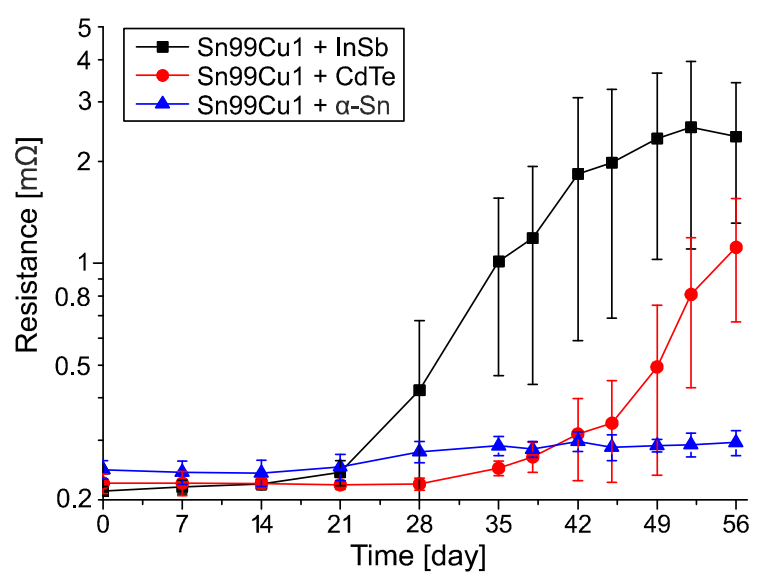

Figure 3: Electrical resistance changes of the Sn99Cu1 samples during 8 weeks of storage at $-10^{\circ} \mathrm{C}$.

During the rest of the study, the samples with different inoculation showed very different behavior. The samples with InSb inoculation showed a considerable resistance increase between 3-6 weeks (in the growth phase). After 6 weeks, the changes of the resistance increase reached the saturation phase. After 8 weeks, the samples started to decompose (Fig. 4). The decomposition of the samples usually occurred when the electrical 
resistance had increased of 25-30 times as compared to the initial value. The highest detected resistance increase of the samples with $\mathrm{InSb}$ inoculation was $\sim 33$ times $(8.3 \mathrm{~m} \Omega)$ after 8 weeks of storage at $-10^{\circ} \mathrm{C}$.

In the case of Sn99Cu1 samples with CdTe inoculation, considerable increase of the electrical resistance was noticeable between the 5-8 weeks of the study. In this case no saturation phase was observed (Fig. 3). Di Maio and Hunt found similar results in the case of different $\mathrm{SnCu}$ alloys inoculated with $\mathrm{CdTe}$ [11]. Here, the highest resistance increase was $\sim 32$ times $(8.13 \mathrm{~m} \Omega)$ after 8 weeks of storage at $-10{ }^{\circ} \mathrm{C}$. After 8 weeks the decomposition of the samples begun.

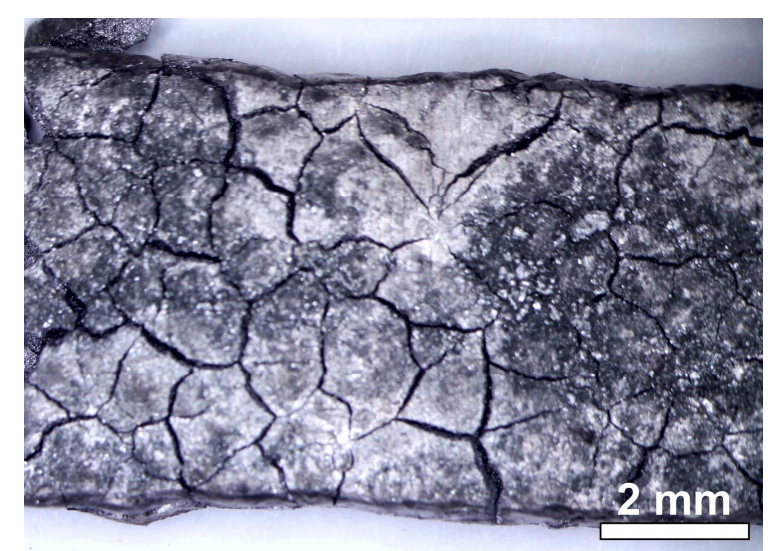

Figure 4: Decomposed Sn99Cu1 sample with InSb inoculation after 8 weeks of storage at $-10^{\circ} \mathrm{C}$.

Generally, the high deviation of the electrical resistances of the samples with InSb and CdTe inoculation is the result of the not totally even inoculation, and the autocatalytic nature of the transition. The differences in the appearance of $\alpha-\mathrm{Sn}$ on the samples result in differences in the transition rates.

In the case of $\alpha$-Sn inoculation, after the moderate (5-20\%) resistance increase at 4 weeks, no further changes were detected. The highest resistance increase was $\sim 0.4$ times $(0.351 \mathrm{~m} \Omega)$ after 8 weeks of storage at $-10{ }^{\circ} \mathrm{C}$. Here, the decomposition of the samples was not observed at all, the transition could not develop in the whole sample volume and it was limited only on the surface of the samples.

Fig. 5 shows the average electrical resistance changes of SAC0307 samples inoculated with InSb, CdTe and $\alpha$-Sn in logarithmic scale. The samples inoculated with InSb and CdTe were totally resistant to the transition, no any visible tin pest signs or electrical resistance changes during the study were observed. In the case of SAC0307 samples inoculated with $\alpha$ - 
Sn, similar effect was observed as at the Sn99Cu1 samples inoculated with $\alpha$-Sn. The first tin pest warts appeared after 2 weeks of storage at $-10^{\circ} \mathrm{C}$ (Fig. 6) and after 3 weeks $15-25 \%$ resistance increase was detected, without any considerable changes later (Fig. 5).

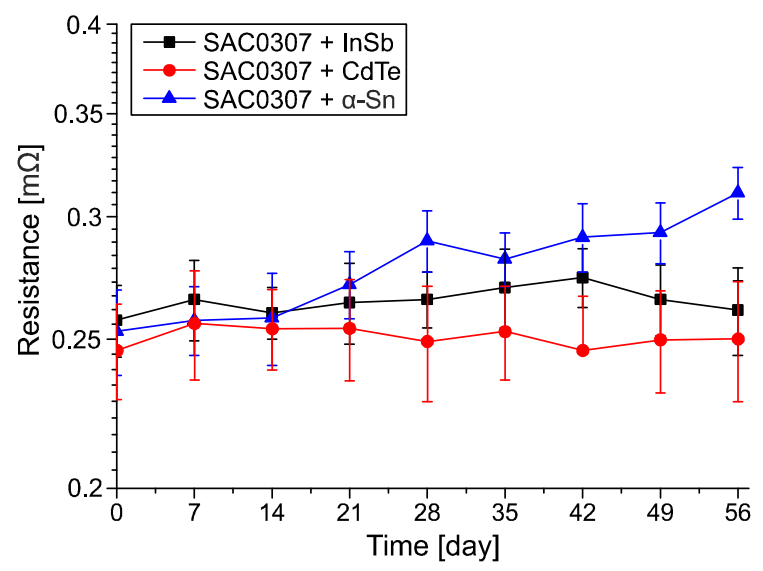

Figure 5: Electrical resistance changes of the $\mathrm{SAC} 0307$ samples during 8 weeks of storage at $-10^{\circ} \mathrm{C}$.

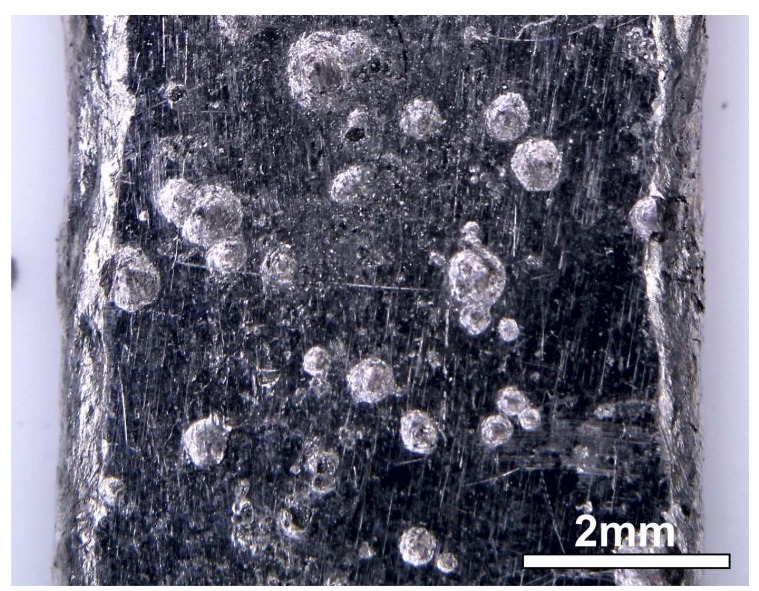

Figure 6: Tin pest warts on the SAC 0307 samples inoculated $\alpha$-Sn after 3 weeks of storage at $-10^{\circ} \mathrm{C}$.

According to the obtained results, two main findings can be concluded: i) the $\alpha$-Sn inoculation resulted in the allotropic transition at both alloy, however the resistance changes were moderate; ii) the InSb and CdTe inoculation resulted in considerable and fast changes but only in the case of the Sn99Cu1 alloy. In order to explain the followings, metallurgical cross-sections were prepared from the samples.

Fig. 7 shows the cross-sections of Sn99Cu1 samples inoculated with $\alpha-S n$ (Fig. 7a) and InSb (Fig. 7b) after storage at $-10^{\circ} \mathrm{C}$ for 8 weeks. In the case of $\alpha$-Sn inoculation, the 
transition does not develop into the whole sample volume, it was limited to the surface of the samples, causing the peeling of the outer layer of material after a while. In the case of InSb or CdTe inoculation, the inoculators can diffuse into the sample body, so the allotropic transition starts at several places inside the sample body and not only on the surface (Fig. 7b), finally leading to the decomposition of the sample. The-brittle $\alpha-S n$ is not visible in Fig. $7 b$, due to falling out from the sample during the polishing.

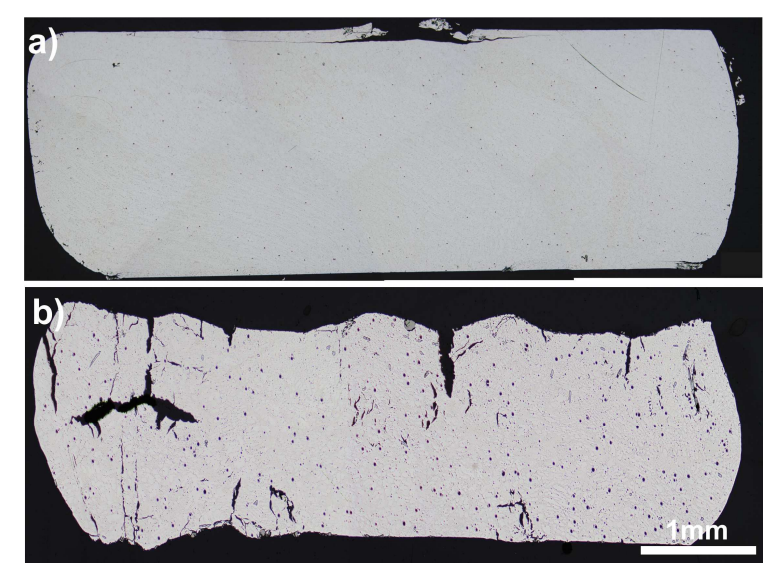

Figure 7: Cross-sections of Sn99Cu1 samples after 8 weeks of storage at $-10^{\circ} \mathrm{C}$ : a) $\alpha$-Sn inoculation; b) InSb inoculation.

Different tin pest susceptibility of the similar solder alloys (Sn99Cu1 and Sn99Ag0.3Cu0.7) might be explained by the Ag content of the SAC0307 alloy. Addition of $\mathrm{Ag}$ to the solder alloy, enhances the creation of $\mathrm{Ag}_{3} \mathrm{Sn}$ intermetallic compounds (IMCs) in the joint after its solidification. Although in the low Ag content solder alloys, the amount of $\mathrm{Ag}_{3} \mathrm{Sn}$ IMCs is relatively lower compared to the classical SAC305 or SAC405, but their dispersion around the grain boundaries of the Sn grains is usually even [12]. The presence of the $\mathrm{Ag}_{3} \mathrm{Sn}$ at the $\mathrm{Sn}$ grain boundaries can decrease the grain-boundary diffusion which results in larger grains and lower number of the grain boundaries. This could decrease the allotropic transition rate. Similar effect of the $\mathrm{Sn}$ grain structure on $\mathrm{Sn}$ whisker growth was already found [13]. However, further research is necessary to prove this theory.

\section{Conclusions}

In this paper, the tin pest susceptibility of the Sn99Ag0.3Cu0.7 (SAC0307) solder alloy was investigated and compared to $\mathrm{Sn} 99 \mathrm{Cu} 1$ alloy with different inoculator materials application. The main findings are the following: the SAC0307 alloy is much less prone for the Sn transition than the Sn99Cu1. This might be explained with the presence of $\mathrm{Ag}$ in the 
solder alloy, since $\mathrm{Ag}_{3} \mathrm{Sn}$ IMCs can decrease the grain-boundary diffusion. Therefore, from reliability aspects, silver cannot be totally eliminated from solder alloys. Furthermore, process of the allotropic transition highly depends on the inoculator material. The non-Sn inoculators can diffuse into the body of the samples and start the transition inside the samples as well, which can lead to the fast decomposition of the samples. In the case of $\alpha-S n$ itself inoculation, the process is limited to the surface of the samples which results in much slower degradation of the samples.

\section{Acknowledgement}

This research was partially supported by the National Research, Development and Innovation Office of Hungary - NKFIH, project ID: FK 127970 and by the Higher Education Excellence Program of the Ministry of Human Capacities in the frame of Nanotechnology and Materials Science research area of Budapest University of Technology and Economics (BME FIKP-NAT).

\section{References}

[1] A. Pietriková, M. Kravčík, "Boundary Value of Rheological Properties of Solder Paste", Proceedings of the 34th Int. Spring Seminar on Electronics Technology (ISSE), Tatra Lomnic, Slovakia, pp. 94-97, (2011).

[2] A. M. Molodets, S. S. Nabatov, "Thermodynamic Potentials, Diagram of State, and Phase Transitions of Tin on Shock Compression”, High Temperature, Vol. 38, No. 5, pp. 715$721,(2000)$.

[3] W. Plumbridge, "Recent Observations on Tin Pest Formation in Solder Alloys", Journal of Electronics Materials, Vol 37, No. 2 pp. 218-223 (2008).

[4] S. Gialanella, F. Deflorian, F. Girardi, I. Lonardelli, S. Rossi, "Kinetics and microstructural aspects of the allotropic transition in tin", Journal of Alloys Compounds, Vol. 474 pp. 134-139, 2009.

[5] A. Skwarek, B. Illés, B. Horváth, A. Géczy, P Zachariasz, D. Bušek, "Identification and caracterization of $\beta \rightarrow \alpha-S n$ transition in SnCu1 bulk alloy inoculated with InSb", Journal of Materials Science: Materials in Electronics, Vol. 28 pp. 16329-16335, (2017)

[6] A. Skwarek, P. Zachariasz, J. Kulawik, K. Witek, "Inoculator dependent induced growth of $\alpha$-Sn”, Materials Chemistry and Physics, Vol. 166, pp. 16-19, (2015). 
[7] D. Giuranno, S. Delsante, G. Borzone, R. Novakovic, "Effects of Sb addition on the properties of $\mathrm{Sn}-\mathrm{Ag}-\mathrm{Cu} /(\mathrm{Cu}, \mathrm{Ni})$ solder systems", Journal of Alloys Compounds, Vol. 689, pp. 918-930, (2016).

[8] A. Pietriková, M. Kravčík, Investigation of Rheology Behavior of Solder Paste, Proceedings of the 35th Int. Spring Seminar on Electronics Technology (ISSE), Bad Aussee, Austria, pp. 138-143, (2012).

[9] B. Medgyes, P. Tamási, F. Hajdu, R. Murányi, M. Lakatos-Varsányi, L. Gál, “Corrosion investigations on lead-free micro-alloyed solder alloys used in electronics", Proceedings of the 38th Int. Spring Seminar on Electronics Technology (ISSE), Egerszalók, Hungary, pp. 296-299, (2015).

[10] X Zhong, L Chen, B Medgyes, Z Zhang, S Gao, L Jakab, "Electrochemical migration of Sn and Sn solder alloys: a review", RSC Advances, Vol. 7, No. 45, pp. 28186-28206, (2017).

[11] D. Di Maio, C.P. Hunt, "Monitoring the Growth of the $\alpha$ Phase in Tin Alloys by Electrical Resistance Measurements", Journal of Electronic Materials, Vol. 38, No. 9, pp. 1874-1880, (2009).

[12] O. Krammer, T. Garami, B, Horváth, T. Hurtony, B. Medgyes, L. Jakab, "Investigating the thermomechanical properties and intermetallic layer formation of $\mathrm{Bi}$ micro-alloyed low-Ag content solders", Journal of Alloys and Compounds, Vol. 634, pp. 156-162, (2015).

[13] B. Horváth, B. Illés, T. Shinohara, G. Harsányi, "Whisker Growth on Annealed and Recrystallized Tin Platings", Thin Solid Films, Vol. 520, pp. 5733-5740, (2012). 
